\title{
An Approach to Improve Quality of Life and Sustainability in the Centers of Old Cities
}

\author{
Tarek Abou Ouf ${ }^{1}$ and Abeer Makram ${ }^{2}$ \\ 1. Department of Islamic Architecture, Umm El Qura University, Makkah 21955, Saudi Arabia \\ 2. Department of Architecture, Delta University for Science and Technology, Gamasa 35712, Egypt
}

\begin{abstract}
The centers of old cities have a special design with a unique urban fabric to record cultural messages with their current citizens or their visitors from the different regions of the city or from outside. It creates spaces that strongly promote social and cultural behavior. Meanwhile, life developments and the stunning technological acceleration along with high population densities have led to many problems for the old cities and their centers, which were not prepared to address these problems. Most of these problems have caused much visual deterioration and economic recession for the centers of old cities, which raise the importance of finding alternative and flexible solutions to prevent damage in urban performance, environmental pollution and lack of requirements that affect the quality of life. The paper aims to present a vision that opens up prospects for subsequent research contributions that may contribute to improving the quality of life, inspired by sustainability and humanization features. The research relies on an inductive analysis method to develop a framework that contributes to the restoration of the old centers for their role, their aesthetic value and their functional importance, while facilitating movement and supporting their valuable architectural features.
\end{abstract}

Key words: The centers of old cities, social behavior, quality of life, humanization, sustainability, aesthetic value.

\section{Introduction}

The importance of centers of old cities lies in the possibility of preserving as much memory as possible to generate feelings of identity through function and belonging, and hence they can be considered as a basis for innovation for the whole city.

Thinking about these old centers is not considered as a regression to what it was in the past or what it is today, but it must be seen as a consciously conducted project for the future, that is, a social subject with a conscious will [1].

The problem of the old centers of historic cities is the inability of their urban structure to cope with the changes in the social, environmental and economic structure, which has affected their visual attractiveness and caused the reduction of their functional role as well

Corresponding author: Abeer Makram, Ph.D., assistant professor, research fields: sustainable architecture, theories of architecture, and architecture design. as the decline and deterioration of the level of services.

In addition, the urban polarization does not match with the old content, which resulted in:

(1) The obliteration of an identity that has been formed over time in urbanization, events and memories.

(2) Cessation in the functional role and the loss of importance that was supposed to keep pace with changes in the economy and culture. With the rapid urban growth, the centers of the old cities suffered either a change in their structure, marginalization of their role, pressure on the original functions for which they were created, or replacement of one of their components which was one of the sources of its identity. The emergence of new centers in other locations of the city, which are able to fulfill the requirements of the population and to face the speed of movement and greater volumes of activities, has made the old centers of these cities vulnerable to neglect, deterioration in services and loss of attractions and vitality of social, economic, and cultural activities. 


\section{Centers of Old Cities-Concept and Role}

The centers of old cities represent civilization nodes for cities that grew and developed in successive stages. Those nodes were live centers with symbolic esthetic dimensions and spaces surrounded by architectural monuments, including the built environment, various activities and daily living experience of the inhabitants and visitors of the place. In addition, they played roles that suited the conditions of life at that time, met the needs of the human with the continuity of social life, and supported the city's roles for economic returns and high cultural values [2].

These centers had a great role throughout the ages in the planning of the city. The Agora yard in Greece or the forum of the Romans was a religious, political and economic center and a place for celebrations, elections, war decisions and the application of the provisions of the law.

In the Islamic Renaissance cities, these centers became the site of the royal palace and the mosque, due to their proximity to schools, public baths, bumaristans (hospitals) and khans (hostels).

In the European Middle Ages, these centers overlooked the churches, the royal palaces and the saints' graveyards. There was no much difference in the ages of the Renaissance as a formal plaza overlooking the palaces of the princes was formed from which the main streets of the city, which was called the Bolivar, were built.

After the development of the industrial revolution and up to the twentieth century, the centers of cities became areas of trade, management, tourism, culture, sports and leisure.

\subsection{Manifestations of the Change in the Centers of Old Cities}

The centers of the old cities are important for preserving memory and belonging. These centers tend to form an urban identity for the rest of the city, such as the historical areas represent the entire city due to a large number of historical and heritage buildings and archaeological sites. Thus, the center of the city represents and reveals the economic and environmental performance of the city [3].

As change in general is one of the most important features of life, and in cities, this change occurs over time due to the changing economic, social and technical factors, especially in the decline of the old as well as diminishing or neglecting its role. Nonetheless, the interest begins to get a new place and the urbanists may notice the change in its beginnings. The question is how to deal with it, and start the preparation of a careful scientific planning to accommodate the development or adapt to the current situation, and even invest and exploit it positively and at best [2].

On the contrary, if decision makers along with design and urban planning experts are not aware of the features of change and the decay of these centers at a time when new centers are emerging as the city grows, the following negative changes [4] on the old centers may be observed:

- Visual damage as a result of negligence or non-directed development processes;

- Deterioration of construction due to misuse of buildings, lack of maintenance plans and programs and periodic follow-up;

- The low level of architectural appearance especially for buildings of value, with a clear contrast between old and the newly established models;

- Interference of incompatible uses to the degree of replacing certain activities with others, which may not be appropriate for the nature and history of the place;

- Isolation of the community resulting from discontinuity and weak communication between the old urban fabric of the city and extension and urban development, which led to a loss in the balance of the social construction of these centers;

- High levels of pollution, especially in cases of accumulation of garbage and waste, the result of increased population density, the disappearance of population awareness, low level of belonging on one hand, and the weakness of the garbage collection 
system on the other;

- The migration of indigenous people to the older centers that have become a more commercial feature. In addition, economic conditions have shifted to a false stability and high values. These people are replaced by low-income residents, resulting in reduced employment opportunities, low levels of maintenance and lack of attention to development;

- One of the most important manifestations of change in the old centers is the entry of modern means of transportation, which may not be commensurate with the existing traffic and transport network, leading to traffic congestion, pollution and low safety.

\subsection{Factors of Deterioration of Old Centers}

The factors of change can be summed up in the following points [5]:

- Urban growth and functional transformation;

- Change in the pattern of movement, transport and transportation;

- Recession of old trade quality;

- Loss of visual attraction;

- An imbalance in cultural growth between old and modern;

- Demographic change breached the balance in social construction.

\subsection{The Approach to Restore the Performance of the Old Centers}

Through reading the manifestations and factors of change in the performance of the old centers of historic cities, the research proposes two approaches to develop these centers in order to restore their social role and improve the architectural image.

First approach: increasing the volume of resources. Second approach: adjusting the volume of demand.

(1) Increase the Volume of Resources

This approach is presented as a logical and intuitive solution at first glance. It depends on making a change with one of the policies of intervention for "urban renewal" [3], whether the re-development or rehabilitation. The economic variables are taken into account in terms of commercial and administrative activities, the cultural variables as the tourist attractions, in addition to the improvement of the architectural condition, through the restoration and consolidation of buildings with distinctive models, restoration of the details and the improvement of the condition of construction. This approach requires large economic resources and may result in high demand for these centers and the recovery of the economic condition.

(2) Adjusting the Volume of Demand

This approach may seem to freeze or diminish the performance in the current time, but in fact it is meant to reduce and control the intensity of use in order to balance the dynamicity of economic movement and ecological requirements, focusing on human aspects, and making the place more suitable for human scale, to be able to have fun with the development of capabilities and practice of social life.

\subsection{Conflict between Sustainability and the Environment of Old City Centers}

One of the concepts of sustainability as defined by Norton: They represent the dynamic relationship between economic systems, human systems and ecosystems (economics, society and the environment). Ecosystems are usually dynamically slower, so human systems seeking to prosper must be codified within certain limits that do not harm the environment. This may be the problem of the centers of old cities. It can be concluded that the development of human systems came at the expense of the concepts of health and environmental safety, which contributed to the overgrowth and prosperity, thus bearing the burdens of the conflict between the economic dimension and environmental, social and cultural dimensions [6].

\subsection{Humanization of Old Centers}

The high population density in these centers, overlapping uses, conflict of activities, as well as the control of cars and vehicles movement on the main 
roads of movement led to adverse environmental changes and effects, increased the level of nervous tension for the inhabitants and visitors, and reduced the level of safety, which in turn led to a decrease in the quality of life.

As time passed, the speed of movement, with a focus on financial and economic goals, became one of the most important factors of social isolation. These centers no longer played a role in cohesion among the members of society. On the contrary, they added levels of visual deterioration and loss of the individual scale, especially after the removal of some old buildings to be replaced by buildings that no longer support the spatial dimension and do not play the role of architectural dialogue between the elements and components of those urban spaces.

As Joel Kotkin puts it in his book The City of Man: "The combination of city, the countryside, and the most humane and family-friendly projects are largely applicable". The study suggests that the older centers of cities have a greater chance of applying the humanistic principles. Thus, the idea of "increasing the volume of resources" or "reducing the volume of demand" can be replaced by the idea of "demand control" in regard to the use of those places [7].

The development of human systems came at the expense of health and environmental safety concepts, which may have helped to increase growth and economic prosperity temporarily. However, the centers of old cities bear the burden of conflict between the economic dimension and the other environmental, social and cultural dimensions as mentioned earlier.

\section{Improving the Quality of Life and Sustainability of Old City Centers}

In 1997, the World Health Organization (WHO) submitted a 20-step report entitled Healthy Cities Project [8]. These steps are related to the following steps of the study:

- Achieve a clean and safe physical environment;

- Provide a sustainable and stable ecosystem;
- Create a strong community with mutual support among its members;

- Ability to meet basic needs;

- Create a diversified, dynamic and innovative economy;

- Encourage communication with the past and cultural heritage;

- Encourage community participation;

- Promote awareness of positive health thinking to reduce diseases.

\subsection{Humanization and Sustainability}

The idea of humanization adopts a number of values and principles, including familiarity and empathy, coexistence, solidarity, respect and entertainment, as well as appreciation of beauty. While sustainability focuses on the idea of balance between economic needs and the need to protect the surrounding environments [9].

Sustainability is not only related to the environment, but to the health of communities and the absence of suffering as well. Similarly, it focuses on the necessity of selecting long-term effects and raising questions of how to improve the quality of life at the present and future time.

By presenting the two concepts - sustainability and humanization - it is clear that they are sharing the idea of "A better quality of life".

\subsection{Associate Factors of Quality of Life in Old City} Centers

All countries that are interested in the future of the coming generations are concerned with the concept and aspects of sustainability and its application in the development processes. Thus, they relied on several pillars, such as justice and equality between generations, environmental balance and the rationalization of consumption of resources, raising the aesthetic value, improvement of the quality of life of the individual, rooting the concept of participation and cooperation and careful consideration of the human heritage. 
The old centers of historic cities are among the top priorities of the governments, systems, research centers, as well as urban, economic, social and environmental experts to achieve these applications such as plans to improve the quality of life in Barcelona, Spain and Istanbul, Turkey [10]. The recovery factors of life in these centers are the following:

\section{(1) An Integrated Walkway System}

Human systems have grown starting from the use of the car to the increased transport operations. Therefore, the paths of the movement inside the centers became unable to bear the high traffic densities, and the consequential increased air pollution levels, against the low safety levels, in addition to the diminish of open spaces and green areas along with the decrease of the necessary oxygen ratios. In contrast, the level of carbon dioxide is rising. In addition to increasing "warming rates", the chances of disease spread are getting higher and most of the centers are becoming unhealthy [11]. Therefore, providing integrated walkway systems and pedestrian streets will increase mobility, enhance road safety, improve local air quality and enhance social benefits.

(2) A Quality Living Environment and Aesthetic Value

Public spaces play an important and pivotal role in promoting our livability, be it as a place for meeting, practicing sports, rest or creative thinking, and due to the decline of open spaces of fields and playgrounds, green areas, and neglect of those areas in old cities and its centers [12]. Thus it needs to improve the management of public space including spaces between buildings (streets, pavements, footbridges, landscaped decks, squares, etc.), parks, podiums, rooftops, etc. and public facility provision as main elements to supply a quality living environment and each has a visual pleasure that adds to the aesthetic value of the place too, Table 1.

In addition to the massive density of building either by demolishing villas or low-rise buildings and their replacement with high-rise buildings which may not enjoy any aesthetic aspect and lack of interest in the historical and heritage vocabulary. All of this come from the absence censorship or weak enforcement of the law in some cases and the absence binding rules to compel land owners in these areas to take into account the architectural image of value or heritage. All this led to the loss of the aesthetic value which is one of the most important foundations of the application of sustainability as well as its ability to sustain the healthy social life.

(3) The Inherent Activities and the Value of the Place

At the same time, the prices of the authorized places for trade, either by ownership or rent system, have increased so the inherent activities, which had a role in upgrading the value of the place, have diminished. These activities have established great meanings and interaction with the population and visitors, deepened memories and strengthened ties of belonging. However, these activities turned into consumptive activities of low value to meet the requirements of the age, to obtain

Table 1 The elements of aesthetic in city centers.

\begin{tabular}{|l|l|}
\hline The elements of aesthetic & \multicolumn{2}{|l|}{ Surfaces (horizontal and vertical), building blocks, plazas and rest area. } \\
\hline Structural elements of the urban escape & Geographical landscape, designed landscape (green areas, water, etc.). \\
\hline Natural elements & $\begin{array}{l}\text { Voice: music, noise reduction. } \\
\text { Texture: smooth, rough. } \\
\text { Smell: smell, perfume. }\end{array}$ \\
\hline Elements of street furniture & $\begin{array}{l}\text { Technical elements: lighting columns and structures traffic lights, phone cabins, etc. } \\
\text { Functional elements: plates significance, bus stations, trash cans, others. } \\
\text { Others: sculptures, toys children, other. }\end{array}$ \\
\hline Service elements & Transportation cleaning and the removal of wastes infrastructure, others. \\
\hline Cultural elements & Historical and heritage elements, civil popularity, cultural and cognitive diversity. \\
\hline
\end{tabular}


income or profit that can withstand resistance, regardless of their role or activities that contributed to the separation of those areas to create an increase with state of urban isolation and social alienation.

The demand for the services provided by those shops increased, at the expense of the demand for the value of the old visual and architectural space.

(4) Community Partnership

When generations succeeded without communication and material became all that governs investment decisions without including the heritage or value within the standards of the development of the place, the concepts of community participation and partnership have fizzled out. Similarly, the phenomenon of cooperation between the residents of those places has diminished, which caused the loss of a cornerstone of sustainability which is the concept of "participation, cooperation and belonging".

\subsection{Application Example: Improving the Quality of Life of the City Center of Barcelona}

Urban renewal and the preservation of old city centers greatly enhance the quality of the environment as a broad umbrella and thus serve as a key motive for change. The development projects of these centers attract a wide variety of economic activities and competitiveness and thus encourage both residents and visitors to reconsider these areas that have been renovated and rediscovered.

The improvement of the physical construction environment, the social fabric and the urban spaces within the urban structure all contribute to the consideration of these places as places for the public and their activities and increase social interaction and cohesion among citizens. In addition, the preservation and renewal of city centers affirms citizens' sense of identity and belonging.

In the early $1980 \mathrm{~s}$, one of the main priorities of the local government of Barcelona was to improve the social welfare of the districts of the central region [13]. The urban structure of the center of the city of
Barcelona has been developed. In addition, a set of strategies have been adopted for the purpose of urban renewal as well as the improvement of the environmental performance of the historical center of the city by creating an effective and strong administrative structure to coordinate the integrated urban renewal. These strategies are summarized in the following:

- Improvement of natural and built environment with the aim of increasing green areas, gardens and road landscaping (1994: 1998) as part of the strategic plan for the green areas and biodiversity, providing each inhabitant $6.2 \mathrm{~m}^{2}$ with the exception of Closierola Park or adding it for the ratio to become $18 \mathrm{~m}^{2}$ for each inhabitant [14];

- Integrated management of Barcelona for regular inspections such as water analysis, recycling of waste and ensuring strict enforcement of environmental laws;

- Urban renewal and rehabilitation of the old city in order to avoid the displacement of the population and to maintain social cohesion with the restoration of squares, open spaces and gardens, the introduction of cultural values and the inclusion of large segments of citizens in the urban transformation project to promote public participation and solidarity of the city, in order to improve the quality of life [13];

- The development of public areas to accommodate the activity of pedestrians and increase the number of lanes for bicycles, the proportion increased from $7.3 \mathrm{~km}$ to $124.4 \mathrm{~km}$ from 1990 to 2004 , which shows that nearly half of the population depends on the pedestrians and bike paths;

- Reliance on renewable energy technology based on technical building code that reduces the use of buildings for energy and mechanization and depends on solar systems;

- Encouraging historic buildings besides the new ones, to work in the field of energy as the city is exposed to very high solar energy. The law in Barcelona provides at least $60 \%$ of the demand for hot water with solar thermal energy; 
- Improvement of the visual impact and reduction of pollution through waste management using the air waste collection system with waste suction systems with different openings for the effective distinction of waste, including a series of interconnected underground pipes and then treated in central treatment plants;

- Improvement of ambient air quality by improving transportation. It is a major source of air pollutants. Therefore, motor traffic is reduced by reducing car movement, encouraging investment in transport sectors, improving road discipline, and providing high quality integrated public transportation to achieve the principles of health and safety using less pollution fuel and controlling the noise resulting from traffic;

- The diversity of public transport networks of metro lines, railways, buses and tram line and using bicycles as a regular transport [14];
- Improving information and equipment for citizens such as traffic lights, road signs and signs throughout the center;

- Encouraging implementation of urban management model as public-private partnership.

\section{Discussion and Conclusion}

There will be no indicators to improve the quality of life unless the principles of sustainability are applied at the economic, social and environmental levels. These areas will continue to be under endless pressure to lose the opportunity to be humanizable, that is to become areas with features that would encourage the country to allocate a share from its resources in order to restore their role and motivate their inhabitants and leaders to resort and belong to them in order to obtain the architectural urban spirit that they lacked long ago during the development, growth and widespread of

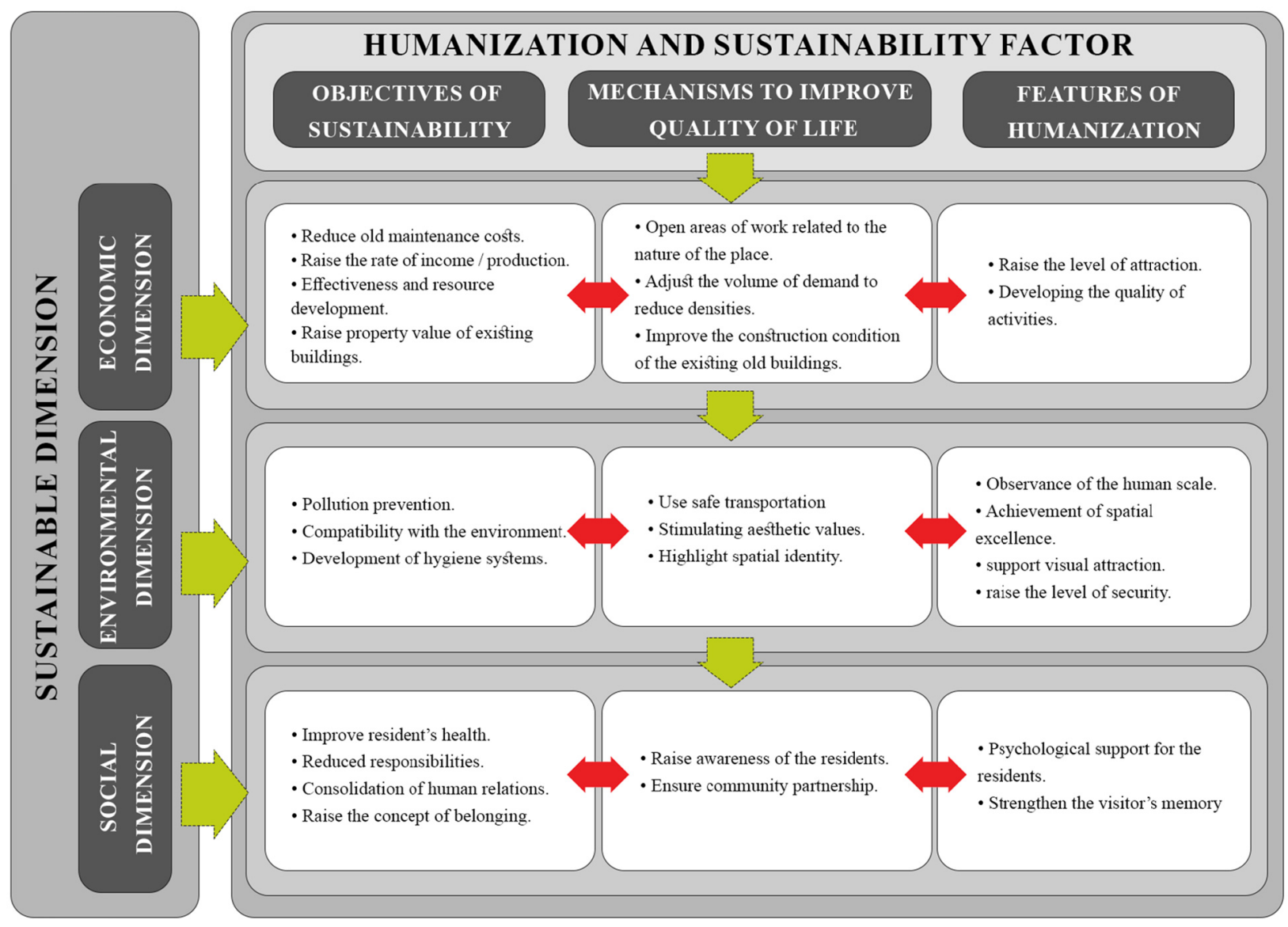

Fig. 1 Conceptual framework to improve the quality of life and sustainability in the centers of old cities. 
urban acceleration of city centers, which happened suddenly or sometimes gradually without regard to the importance of the humanist scale, and to health care, restoration of heritage buildings to its value, while reducing the terrible inequalities in environmental equilibrium, which will undoubtedly threaten the idea of "improving the quality of life".

Each old city center has its own memories and activities on which historical cities are based. All studies highlight the importance of the old centers of historic cities, which play a key role in establishing the rules of beauty, strengthening social ties and ending the state of social isolation, while reinforcing the concept of the memory of the city, all functions that new centers may not be able to do at the same level as the old centers where it is difficult to apply concepts and aspects of quality of life. This may happen due to several factors, including the nature of urban fabric, the network of motor traffic, rapid urbanization, and the quality of commercial, administrative and recreational activities.

Therefore, the hope of restoring and improving the quality of life in the old centers is closer to achieve in reality because of the appropriateness of its human scale, the qualitative restoration of the rich image and the ease of achieving community belonging.

When relying on measures to improve the quality of life in the centers of old cities, which result from focusing on some of the goals of sustainability in an attempt to restore the features of humanization, these centers regain their social role and reduce the size of the conflict between the economic and ecological dimensions.

In the context of the study, it is possible to propose a conceptual framework (Fig. 1) that links the objectives of sustainability with the mechanisms of improving the quality of life and the characteristics of humanization of the available economic, social and environmental dimensions. Therefore, this framework acts as an approach for the development of the centers of old cities.

\section{References}

[1] Carrion, F. M. 2005. "The Historical Centre as an Object of Desire." City \& Time 1 (1): 3.

[2] Jawad, S. A. H. 2011. "Change in the Historical City Centers." Journal of Planning and Development, p. 24.

[3] Brazil, I. 1987. "First Brazilian Seminar about the Preservation and Revitalization of Historic Centers."

[4] Karacor, E. K., and Koylu, P. 2014. "Urban Life Quality as an Approach to Sustainability: the Case of Duzce City." The Sustainable City IX 1: 403-13.

[5] Al-Harbi, A. 2010. "Planning Characteristics of Arab Cities Centers, A Planning Study for Riyadh City Center." College of Architecture and Planning, King Saud University.

[6] Wehrmeyer, W., and Mulugetta, Y. 2017. Growing Pains: Environmental Management in Developing Countries. Routledge.

[7] Risom, J. 2013. "Sharing Economy for People, The Role of People First Design." MSc City Design and Social Science, Architectural Engineer.

[8] WHO. 1997. Twenty Steps for Developing a Healthy Cities Project (No. EUR/ICP/HSC 644 (2), Copenhagen. WHO Regional Office for Europe.

[9] Forte, B., et al. 2003. The Human Sustainable City: Challenges and Perspectives from the Habitat Agenda. Routledge.

[10] Türkyılmaz, C. C. 2013. "What Make Cities Sustainable? Barcelona and Istanbul.” The Sustainable City VIII 1 (1).

[11] Hong Kong 2030. 2016. "Planning and Urban Design for a Livable High-Density City." Planning Department.

[12] Al-Qaraghuli, A. S., and Al-Hinkawi, W. S. 2016. "Aesthetic Values of the Future Cities." Presented at 2nd International Conference on Architecture, Structure and Civil Engineering (ICASE'16), London, UK.

[13] Arbaci Sonia, B. T. 2012. "Social Inequality and Urban Regeneration in Barcelona City Centre: Reconsidering Success." European Urban and Regional Studies 19 (3): 287-311.

[14] Elnokaly, E. A., Elseragy, A. B., and Saadani, S. A. A. 2009. "Sustaining Historical City Centers through Urban Regeneration." in Proceedings of International IAPS-CSBE \& HOUSING Network, page. 